Check for updates

The BMJ, London, UK

2 BMJ Medicine, London, UK

3. School of Public Health, University of

Washington, Seattle, WA, USA

4. Centre on Climate Change and

Planetary Health, London School of

Hygiene and Tropical Medicine, London,

Correspondence to: J Dobson jdobson@bmj.com

Cite this as: $B M J$ \$ $\{$ year\};375:n2425 http://dx.doi.org/10.1136/bmj.n2425 Published:

\section{Accelerating climate action: the role of health professionals}

\author{
Both individual action and promotion of systemic change are essential \\ Juliet Dobson, ${ }^{1}$ Sophie Cook, ${ }^{2}$ Howard Frumkin, Andy Haines, Kamran Abbasi ${ }^{1}$
}

Despite years of aspirational promises from governments and leaders, we have acted too slowly on the climate emergency. Time is running out to reverse, or even halt, the damage done by humanity to our planet.

Climate change is affecting health now, and the effects will increase greatly in the future depending on the actions we take. ${ }^{1}$ Tipping points, such as ice sheet collapse or methane emissions from melting of the Arctic tundra, coral reef die offs, and alterations of oceanic currents, might be closer than we thought, leading to irreversible damage to biophysical systems with severe consequences for human wellbeing. The Intergovernmental Panel on Climate Change indicates that, even under an intermediate greenhouse gas emissions scenario in which carbon dioxide emissions remain around current levels until 2050, the global average temperature increase is likely to be $2.1-3 \cdot 5^{\circ} \mathrm{C}$ by the late 21st century. This emphasises the urgent need for drastic reductions in carbon dioxide and other greenhouse gases. ${ }^{2}$

When it comes to irreversible destruction of the natural planetary systems that underpin human civilisation, there is no second chance. ${ }^{34}$

In November 2021, more than 200 countries will meet at the 26th UN climate conference (COP26), one of the largest gatherings of world leaders in history, to agree collective action on the climate emergency. The evidence is clear: setting targets is no longer enough. We need to act now, both individually and by holding organisations and governments to account. We need to recognise and communicate the harms to health of the climate emergency, create guidance on how to adapt to the change that cannot be prevented, and prevent further damage through mitigation strategies and by motivating behaviour change.

The relative importance of individual behaviour change and system change is debated. On one side, people advocate making changes, for example, to what we eat, how we travel, and how much energy we use. ${ }^{5}$ Others argue against excessive focus on behaviour, believing that even widespread behaviour change will never be enough and that a focus on individual behaviour detracts from the necessary system changes. ${ }^{6}$ This is a false dichotomy. Change is needed at both levels. Indeed, the two may be mutually reinforcing; taking individual action can energise people to work for system change. ${ }^{7}$ Young climate activists are showing everyone the way. ${ }^{8}$

\section{Many roles of health professionals}

Doctors and other health professionals are in a unique and privileged position to influence change as family members, private citizens, clinicians, researchers, advocates, and leaders. ${ }^{910}$ However, only a small proportion of health professionals feel able to take effective action in response to the climate crisis, with many citing personal and professional barriers, the most important one being a lack of time. ${ }^{11}$ Health professionals are first and foremost family members and citizens, and as individuals they can make simple climate friendly behavioural choices regarding how they live and work, what they buy, what they eat, and how they travel.

As respected community members, health professionals can introduce the climate emergency into conversations, share knowledge, and inform debate. ${ }^{12}$ Doing something tangible can give us hope and purpose, provide relief from the growing problem of climate anxiety, ${ }^{13}$ make us feel part of a collective whole, and help us square up to the challenge that we face. ${ }^{14}$ Patients can be guided to climate friendly behaviours by explaining the benefits to individual and population health.

Healthcare contributes 4-5\% of global greenhouse gas emissions. ${ }^{15}$ In the NHS, $62 \%$ of these emissions are from its supply chains and $24 \%$ from delivery of care. ${ }^{16}$ Health professionals can be institutional leaders who drive decarbonisation in hospitals through reducing overdiagnosis and overtreatment in healthcare, ${ }^{17}$ eliminating waste, streamlining services, ${ }^{18}$ and better managing suppliers and procurement. ${ }^{19}$ All of these efforts will bring us closer to making healthcare more sustainable.

Many of the sustainability initiatives in the NHS were set up by health professionals before they received support from their senior managers or their organisation, with health professionals often taking the lead, identifying areas for improvement, and driving through change. Nonetheless, better education, training, and guidance on how to make clinical practice more sustainable are required, based on the best available evidence. The foundations for establishing best practice in sustainability can be laid by embedding training about the climate emergency in medical school and university curriculums. $^{20}$

\section{Organisational change}

Organisations must play their part. In the UK, the NHS is taking a leading role by declaring ambitious targets to reach net zero over the next two decades. Clinicians will require support to achieve this goal but must also hold the NHS to account and push individual trusts and healthcare practices to take responsibility for reaching climate targets. Many UK medical royal colleges, the BMA, and other NHS organisations have declared a climate emergency. Members of these organisations can demand a clear 
action plan on how to meet the targets and demand regular progress reports.

Climate action must also be promoted by public health professionals working in local government and across other sectors that are responsible for large shares of emissions, such as transport, energy, food and agriculture, and housing. Actions to mitigate climate change in these sectors will deliver benefits for health through reduced air pollution, increased physical activity, and improved diets. $^{21}$

The climate emergency is a multidisciplinary, multisectoral, crisis that transcends professional and organisational barriers. Health professionals can help bring sharp focus to the urgent reforms required from individuals, organisations, and governments. Power rests with governments and entrenched private interests, but people are not powerless. There is no greater crisis than the one posed by the climate emergency. This is a moment for action and leadership. Health professionals must embrace these responsibilities, reaching out to patients, organisations, and colleagues in other sectors to accelerate the pace of change.

Competing interests: We have read and understood BMJ policy on declaration of interests and declare that JD is on the executive of the UK Health Alliance.

Provenance and peer review: Commissioned; not externally peer reviewed.

1 Vicedo-Cabrera AM, Scovronick N, Sera F, etal. The burden of heat-related mortality attributable to recent human-induced climate change. Nat Clim Chang 2021;11:492-500. doi: 10.1038/s41558-021-01058-x pmid: 34221128

2 IPCC. Climate change 2021: the physical science basis. https://www.ipcc.ch/report/ar6/wg1/downloads/report/IPCC_AR6_WGI_SPM.pdf

3 Murage P, Batalha HR, Lino S, Sterniczuk K. From drug discovery to coronaviruses: why restoring natural habitats is good for human health. BMJ 2021;375:n2329. doi: 10.1136/bmj.n2329.

4 Whitmee S, Haines A, Beyrer C, etal. Safeguarding human health in the Anthropocene epoch: report of The Rockefeller Foundation-Lancet Commission on planetary health. Lancet 2015;386:1973-2028. doi: 10.1016/S0140-6736(15)60901-1 pmid: 26188744

5 Williamson K, Satre-Meloy A, Velasco K, Green K. Climate change needs behavior change: making the case for behavioral solutions to reduce global warming. Rare, 2018.

6 Hagmann D, Ho EH, Loewenstein G. Nudging out support for a carbon tax. Nat Clim Chang 2019;9:484-9. doi: 10.1038/s41558-019-0474-0 .

7 Mark J. Yes, actually, individual responsibility is essential to solving the climate crisis. Sierra 2019 Nov 26. https://www.sierraclub.org/sierra/yes-actually-individual-responsibility-essential-solvingclimate-crisis

8 Dobson J. Youth activism for health: taking the future into their own hands. BMJ2019;367:16881. doi: 10.1136/bmj.l6881 pmid: 31848183

9 Maibach E, Frumkin H, Ahdoot S. Health professionals and the climate crisis: Trusted voices, essential roles. World Med Health Policy 2021;13:137-45. doi: 10.1002/wmh3.421.

10 Maibach E, Miller J, Armstrong F, etal. Health professionals, the Paris agreement, and the fierce urgency of now. J Climate Change Health 2021;1:100002. doi: 10.1016/j.joclim.2020.100002.

11 Kotcher J, Maibach E, Miller J, etal. Views of health professionals on climate change and health: a multinational survey study. Lancet Planet Health 2021;5:e316-23.

doi: 10.1016/S2542-5196(21)00053-X pmid: 33838130

12 Ipsos MORI Veracity Index. 2020. https://www.ipsos.com/ipsos-mori/en-uk/ipsos-mori-veracityindex-2020-trust-in-professions

13 Mala R. The climate crisis and the rise of eco-anxiety. BMJ opinion, 6 Oct 2021 https://blogs.bmj.com/bmj/2021/10/06/the-climate-crisis-and-the-rise-of-eco-anxiety

14 Singh C. Individual action versus systemic change: lessons from COVID19 for climate change. 22 Apr 2020. https://socialsciences.nature.com/posts/66491-individual-action-versus-systemicchange-lessons-from-covid19-for-climate-change

15 Watts N, Amann M, Arnell N, etal. The 2019 report of The Lancet Countdown on health and climate change: ensuring that the health of a child born today is not defined by a changing climate. Lancet 2019;394:1836-78. doi: 10.1016/S0140-6736(19)32596-6 pmid: 31733928

16 Tennison I, Roschnik S, Ashby B, etal. Health care's response to climate change: a carbon footprint assessment of the NHS in England. Lancet Planet Health 2021;5:e84-92. doi: 10.1016/S2542-5196(20)30271-0 pmid: 33581070

17 Barratt A. Overdiagnosis is increasing the carbon footprint of healthcare. BMJ2021;375:n2407. doi: 10.1136/bmj.n2407

18 Royal College of Physicians. Less waste, more health: A health professional's guide to reducing waste. 2018 https://www.rcplondon.ac.uk/projects/outputs/less-waste-more-health-healthprofessionals-guide-reducing-waste
19 Royal College of Physicians. Less waste, more health: Procurement 101. 2018. www.rcplondon.ac.uk/news/less-waste-more-health-procurement-101

20 Moore A. A planetary health curriculum for medicine. BM/2021;375:n2385. doi: 10.1136/bmj.n2385

21 Haines A, McMichael AJ, Smith KR, etal. Public health benefits of strategies to reduce greenhouse-gas emissions: overview and implications for policy makers. Lancet2009;374:2104-14. doi: 10.1016/S0140-6736(09)61759-1 pmid: 19942281 